\title{
Final Comments: Objects of Governance as Simultaneously Governed and Governing
}

\author{
Helen Verran \\ Professorial Research Fellow \\ Northern Institute \\ Charles Darwin University \\ helen.verran@cdu.edu.au
}

\section{Michael Christie}

Professorial Research Fellow

Northern Institute

Charles Darwin University

michael.christie@cdu.edu.au

Keywords: Objects of governance, Aboriginal, firing, land management, ethics, environmental science, dissensus

In 2013 a perplexity we had been experiencing for some time around the apparently unstoppable proliferation of contexts in which "the public problem" of Indigenous governance emerged came to a head. As members of an informal consultancy team established within the Contemporary Indigenous Knowledge and Governance Group in the policy research institute where, near the ends of our careers, we find ourselves based, we were asked by a group of concerned government officers - both Federal and Territory, to intervene in 'governance training' in five Aboriginal communities. Top-down delivery of Government funded training services on a fly-in-fly-out basis has become a huge industry in Aboriginal Australia, yet a bad smell of failure persistently hangs around these programs. The amount of funding we were offered for our work was significant, but still the size of a 'rounding error' in government budgets for governance and leadership training in Australian Aboriginal communities. And like much useful research funding, it was offered to us at short notice, at the end of a financial year. Our very different research-informed approach to services delivery was seen as an alternative to what was not working, and we were approached by people in government with whom we had established relations of confidence and trust. Contracts were duly signed and we found ourselves deeply involved with a group of younger scholars in delivering the 'Indigenous Governance Development and Leadership Project' (IGDLP). This in part is the origins of our writers 'workshop on objects of governance, and this volume.

While that 2013 writers' workshop and this collection of papers emerge as part of our response to the challenge of thinking about governance, there are also other emerging practices and structures. Another outcome of the challenge we felt on beginning this project is a Governance Lunchtime Discussion Group. This group arose from the sense, voiced urgently by Juli Cathcart, a member of our IGDLP project that many other groups in our policy research institute were 'working on governance' and we never talked to each other about it. This scholarly isolation was clearly an expression of the phenomenon we were grappling with in the IGLDP project. Our governance as a scholarly community is significant surely. The papers here express the work of this collective as much as the discussions of the writers' workshop, which having been held in August 2013, are by now a fading influence.

In this summing up end-paper we first consider what, when taken together, the papers might offer the reader who is puzzled about the relatively recent emergence of the pervasive concern with governance in Australia (and internationally), particularly governance in northern Australia and its Aboriginal communities. Then we look at the papers as we have loosely grouped them 
around themes emerging from 'stories' from other times and places (usually known as theory) which have informed our thinking and writing about objects of governance. These are the texts of philosophers Michel Serres, Michel Foucault, and Kathryn Pyne Addelson. In concluding we briefly consider what the analytic approach displayed here in the form of eight short papers, might offer in terms of generative engagement with the new "Indigenous Advancement Strategy" - the first stage of which is about to be operationalised by the Federal Government.

So what does this collection of rather short analytic texts offer? One insight the collection allows concerns the initial confusion that accompanied our call for expressions of interest in attending a writers' workshop on objects of governance. Did we mean objects that were governable or objects that in some way governed? In asking potential participants to write on an object of governance were we asking them to write about an object that could, or perhaps should, be governed? Were we asking for ideas on how norms might be instituted in rules of governance? Or, were we asking them to write about objects that somehow were involved in the actual work of governing, seeming to have some agency? This response to our question raises a debate that is very old in Western thought. Do things drive history, or do particular historical periods call forth particular technologies. This is the technological determinism/ social shaping question that flourished in the academy during much of the $20^{\text {th }}$ century.

The texts collected here show a way out of that sterile $20^{\text {th }}$ century debate - the challenge we were posing was for analysts to consider objects of governance as simultaneously both governing and governed. The writing task we set was to conjure up the 'lives' of complex objects. We hope readers see inspiration in the resulting stories.

In together 'performing' an analytic that focuses on the challenges associated with the new emphasis on governance in many arenas of Australian life through a focus on the objects that "do" governance in that complex manner, the papers here exemplify an analytic framing that is perhaps still unusual in Australian analytic talk. This is a framing that sees worlds as emerging all of a piece in the present - governed and governing simultaneously. Here the easy assumption of giveness, of an object world "out-there" to be governed and a human world "in-here" which does the governing, exists only as one possible (and costly) accomplishment of a particular mode of modern governance.

The analytic approach to governance and to objects that the papers collected together here exemplify has left that parochial analytic framing of old modernity behind. While this abandonment of giveness is not unusual in academic writing, especially in the humanities and social sciences, it is still unusual in the natural sciences and in the ordinary work of government. Our hope is that the accessible short texts focusing on objects both specific and small (e.g., a cyber safety poster that had a peripheral life in three Aboriginal communities) and vague and large (quality assurance in Australian child care or financial literacy) will begin to change that situation. The stories we have collected here might begin to make the analytic that considers governed and governing as realised simultaneously in the present seem less arcane, its generativity more evident.

Each of the papers, either explicitly or implicitly incorporates a reference to a philosophical text - Serres, Foucault, or Pyne Addelson. In an analytic of giveness such texts are usually identified as 'social theory'. There the idea of theory is juxtaposed with empirics. Theory is supposed to articulate principles of social life in a society that is given and found. In an analytic of emergence the analytic categories of "theory" and "empirics" become something else. By grounding analysis robustly in the present, what (in an analytic of giveness/foundness) used to be 'empirics' becomes 'stories of the here and now'; what used to be 'theory' becomes 'stories from other times and places'. The resources available for analysing the happening of the present either arise in the here-and-now or are carried into the here-and-now from various 
then-and-there's. And in this 'carrying in' great care needs to be exercised. The question "Will this story from that then-and-there implicate us in commitments that will get in the way of us engaging openly with the here-and-now?" needs to be posed again and again. In the context of working with many Aboriginal Australian communities in northern Australia, an example of such a commitment is the commitment most scientists maintain to the figure of matter set in space and time, which is a necessary element in that old modern analytic of giveness/foundness.

The three 'stories from other times and places' that the authors of the texts collected here bring into their analyses arose during the $20^{\text {th }}$ century, in the work of French philosophers Michel Serres (1995) and Michel Foucault (2007), and the American Pragmatist/analytic philosopher Kathryn Pyne Addelson (2002). Having brought Serres' message, an image of a ball playing skillful children in a game, into the time and place of our workshop, we played it as much as it played us. The same could be said of the messages of these other authors, and you see the outcome in the texts we present here. Serres' message becomes entangled with ghost nets that land on the beaches of Aboriginal communities in northern Australia in the early $21 \mathrm{st}$ century, and with stories, and items for sale on an art centre website; with a storied cyber safety poster that circulates, and with multiply textualised land management fires. The same fate befell fragments of Foucault's texts and Pyne Addelson's texts in the texts generated from our workshop.

From within the entanglements of these fragments of text which have mingled and abraded with our own remembered and rearticulated experiences, new stories, insights and ways of seeing began to emerge.

Emily learnt that if we are shown how to dig them out of the sand, we can help make and follow objects of governance. She gradually began to notice how ghost nets become objects of governance as they become bags, and how their reception as art objects depends upon the aesthetics at work in the Aboriginal Art industry. The buyers of the bags buy into environmental politics (saving the nets from their destructive work and drawing attention to the problem through art objects), the utilitarian Aboriginal craft work, the bright but earthy and primitive look, modern-traditional hybrid, the canny art supervisor and the women who had come seemingly from nowhere 'to instruct the artists' in net-working. The bags came to life materially and discursively in particular ways; and understanding that process allowed Emily as a particular sort of scholar, to find opportunities for more and similar collective action with more people and things.

Trevor found that we can help objects of governance come to life if we work well enough with the right people on both sides of the divide. Working with Serres' image of playing ball, a cyber-safety poster can be seen as designed by canny people to promote the work of good governance. Happening in spite of rather than because of government initiatives, allowed the GroundUP team to think and work through the local situated agreement-making-underauthority practices to design a poster which would allow people in the collective action of traditional governance on ancestral ground to collectively design cyber-safety as they engage with the object, each other, and redefine the public problem.

A four year old boy told Mel the meaning of quality assurance at a time when, through the outsourcing of the adjudication of quality infant education, Mel was herself becoming configured as an expert in particular ways. Through her work she was becoming entangled in processes ensuring that she acted independently and safely, amidst and alongside new scientific developments, and in relation to the emergence of neo-liberal educational policy principles ("belonging, being and becoming"). However, it is only as these efforts are reconfigured and revealed as a small Aboriginal boy becomes part of the collective action, that she is also able to discern a thoroughly revised notion of quality reconstituting quality assurance as a quite different object of thought. 
A $19^{\text {th }}$ century climatograph made Chris sweat, and reflect upon his sweating and his engagement with the north. Seen as a technology of governance, the climograph could be recognised as simultaneously produced the livability of colonial settlement, and rendering invisible Indigenous livability and its knowledge of environment and climate. It is by understanding the work of climatograph as produced by and producing a particular governmentality 'then and there' that we might, perhaps, find assistance as engaging openly with the here and now, particularly with local and Indigenous knowledge practices.

Matt Brearley and the other researchers began to deal with heat stress much better by understanding it as multiple. Beginning to notice the ruptures and reconfigurations within Matt's engagement with this strange object, heat stress also begins to emerge as an object which is different in differing contexts, which has both visceral and mathematical manifestations, and as a risk borne unequally by various parties. Perceiving this multiple materiality allows for a more generative political (and ethical) engagement with this object of governance in situated interventions.

Financial literacy becomes another way for Yolnu to show Michael that there is an honourable way of fulfilling multiple accountabilities, differences notwithstanding. As financial Literacy emerges in contemporary governance, financial institutions use it to sell their 'products' and to contribute to the 'increased financial and social well-being' of Aboriginal people. However, at the same time Aboriginal consultants gently set up some discursive and nondiscursive practices which help us see both the 'object of thought' and the researcher within a quite different play of truth and falsehood, and a new understanding of the generative work of good faith.

The Blue House shows Matt Campbell how its multiplicity may allow him to strategise in new ways. The Public Housing blue house is without a history, just a present and a future, achieved through severing its relationships with community, land and other houses, normalising bureaucratic allocation processes and spaces. However, on the other hand, the Aboriginal blue house, being done quite differently by different people at different times, they can be seen as constituted through history, politics, and place. Noticing the work of the Housing Reference Group (HRG) members behind the scenes widens the ensemble cast (the 'criteria') in order to (re)produce an Aboriginal blue house, and the blue house emerges as multiple as the researcher revises his role.

Finally, fire tells Helen how working carefully with those multiples, dealing with them as they emerge, we may find ways of doing our work more ethically. In a retold story of Yolnu and scientists working together using fire for environmental management, carefully preserving dissensus becomes generative in our going on together, not only in good faith, but ethically, as we renegotiate our norms and values in ways resonating beyond the particular problem of the moment.

In amidst a pervasive still growing concern with governance in Northern Australia, these stories have helped us to perform an analytic which has conjured up the 'lives' of complex objects. This is an analytic we have worked with in connecting with some of the challenges arising around a proliferation of new objects and contexts through which Indigenous governance is emerging as a 'public problem' being enacted in various ways.

However, beyond worked accounts generated in this text, is this an analytic that may also offer other avenues for generative engagement?

In 2014, six months after the Objects of Governance workshop had been convened, The Australian Government announced a new Indigenous Advancement Strategy (IAS). The stated aim of this strategy is to reduce Indigenous disadvantage, particularly in remote communities, and commits to allocating $\$ 4.8$ billion over the next four years towards "...achieving better 
results for Aboriginal and Torres Strait Islander Australians in three priority areas - getting children to school, adults into work and building safe communities' (Department of Prime Minister \& Cabinet (DPMC), 2014a).

The promise of the strategy was that there will be "no more off the shelf solutions designed in Canberra" being mobilised to engage with issues arising in remote indigenous communities. Rather a key thrust of the IAS is the "participation" of individuals, groups, agencies and most notably corporations, working particularly to foster regional and place-based approaches to developing joint solutions to presenting problems. Part of the process of allocating funding through this strategy is the streamlining of the over 150 existing programmes and activities through which federal funding flows to indigenous communities and organisations, into five consolidated streams: Jobs, Land and Economy; Children and Schooling; Safety and Wellbeing; Culture and Capability; and Remote Australia Strategies. This consolidation is to provide "unprecedented flexibility" within the means through which funding may be sought and applied for through the strategy (DPMC, 2014b)

Almost anybody with a 'legal personality' is eligible to apply, however, the only sticking point is the "outcome indicators" which, in the guidelines are listed at the bottom of each "program and outcome" and which talk a lot about numbers, percentages and rates (e.g., of attendance). These are a series of targets which are embedded in the policy, and we have been told that our funding applications will be assessed specifically in terms of those "outcomes".

Might thinking with and through objects of governance support us to work generatively with and through this strategy as we grapple with the new objects it is bringing to life?

Our stories help us to notice the strategy as clusters of objects generating complex sociopolitical global-local configurations. And to see the relations of these objects as labile, provisional, and contingent, in a manner similar to that of our own work. Just as we have participated in the production of the objects of governance in this text, we might think of ourselves as both participating in the ongoing production of the strategy, and an effect of it our imaginations, practices and possibilities all in the process of being changed by this new and energetic object.

As we begin to work on grant applications, we are implicitly encouraged to choose which "public problem" to focus on, and who and what our partners might be to help us with theory (then and there) and practice (here and now). Thinking with and through our stories might help to sensitise us, and broaden our vision to some of the scope and variances of our choices as we promote ourselves within the strategy as it emerges. But we may also wait, as we so often have, until we are invited to join collective action on a particular here and now problem. As we do so, we are aware that the notion of "advancement" carried by the Indigenous Advancement Strategy, bears within it a certain deficit model which underlies the push for normalisation; and that while 'public problems' are implicit in the text of the documents, our collective action looks to produce objects which govern and are governed differently.

Working with objects of governance, we are tracing some of the ways in which we engage with governments and the people and places of Northern Australia in terms of what Miller and Rose (1990, p.24) have termed "advanced liberal governmentality" - what others also call more generally neo-liberalism. In Miller and Rose's (1990) terms, the authority of the authors of our collection is increasingly detached from state rule, and we as experts are being 'relocated' in a market governed by the alternative rationalities of 'competition, accountability and consumer demand'. Gone, in this scenario, is the "old public administration ... that combines conscious structural design with an integrated culture" of government (Christensen, 2006, p.448). Structural design and integrated culture are now up to us and to the "heterogeneous communities of allegiance" we may work with through the Indigenous Advancement Strategy. 
So we rethink our reluctant expertise towards a more generative engagement in collective action. We may find the opportunity, (like Emily) to be shown the raw material buried in the sand, and to help make and follow emerging objects of governance which engender healthy sustainable creative remote communities of allegiance and allow us to generate consumer demand for our services as we are simultaneously governed by these objects. Or, (like Trevor) we may help objects of governance come to life to take an active role in the governance work of community Elders over their heterogeneous communities of allegiance which include ourselves.

Small boys like Boris may help us (and Mel) engage more generatively with the changing rationalities of accountability and consumer demand in quality childcare. And strange old objects, like a $19^{\text {th }}$ century 'climatograph', may help us (like Chris) to see the traps and opportunities of mapping and of history getting in the way of open face to face engagement in collective action over problems of the moment. We are beginning to see objects (like Matt's blue house or the other Matt's heat stress) as multiple rather than just multiple views of the one object. And we are struggling to learn how multiple objects (like our environmental fires and "financial inclusion") when taken as fundamentally multiple, may lead us towards more ethical engagements in going on together. We see the dissensus upon which generative theory depends as a special case of the rationality of competition which frees our work in important ways from state rule.

By the time this special edition of our Learning Communities Journal becomes a hard object we may have cast our lot in with one or another of the projects everyone is talking about today. The policies and rules of the Indigenous Advancement Strategies may have changed. We will have.

\section{References}

Addelson, K. P. (2002). The Emergence of the Fetus. In C.L. Mui \& J.S. Murphy (Eds.), Gender Struggles: Practical Approaches to Contemporary Feminism. Lanham, USA: Rowman \& Littlefield Publishers.

Christensen, T. (2006). Smart policy. In M. Rein, \& R. E. Goodin (Eds.), The Oxford Handbook of Public Policy. New York: Oxford University.

Department of Prime Minister \& Cabinet (DPMC). (2014a). Indigenous Advancement Strategy. Retrieved from http://www.indigenous.gov.au/indigenous-advancement-strategy

Department of Prime Minister \& Cabinet (DPMC). (2014b). Indigenous Advancement Strategy: Application kit for funding. Canberra: ACT: Department of Prime Minister and Cabinet. Retrieved from https://www.dpmc.gov.au/sites/default/files/files/ia/ias_application_form_green.pdf

Department of Prime Minister \& Cabinet (DPMC). (2014c). Green Paper on Developing Northern Australia. Canberra: ACT: Department of Prime Minister and Cabinet.

Foucault, M. (2007). Why study governmentality? In M. Senellart (Ed.), \& G. Burchell (trans.), Security, territory, population: lectures at the College de France 1977-1978. Fifth lecture of the annual lecture series given by Michel Foucault in 1977-1978, Paris, France: Palgrave Macmillan.

Miller, P., \& Rose, N. (1990). Governing the Present, Cambridge: Polity.

Serres, M. (1995). Angels. A Modern Myth. Paris, France: Flammarion. 